\title{
VIRTUAL ENVIRONMENT OF LEARNING AS DIDACTIC SUPPORT IN DISCIPLINES OF BIOCHEMISTRY
}

\author{
Maia,W.B. ${ }^{1}$, Martins, J.M. ${ }^{1}$, Furtado, V.C. ${ }^{2,4}$, Araújo, B.C. ${ }^{1}$, Marsden, A. ${ }^{1}$, \\ Pimenta Filho, A.A. ${ }^{1}$, Aquino, I.J. ${ }^{1}$, Silva, L.G.C. ${ }^{1}$, Porto, A.L.F. ${ }^{2,3}$ \\ ${ }^{1} \mathrm{CCB}, \mathrm{CCS}, \mathrm{CCSA}, \mathrm{CIN} / \mathrm{UFPE} ;{ }^{2} \mathrm{LIKA} / \mathrm{UFPE} ;{ }^{3} \mathrm{UFRPE} ;{ }^{4} \mathrm{UPE}$
}

This work was accomplished in UFRPE involving three groups (A, B and C) of disciplines of Biochemistry. It presents an analysis on the teaching online and a discussion theoretical-empirical about virtual environments. The disciplines were posted in www.ensinarnet.com. The content was displayed in web. It was used agenda, chat, forum, mural and classroom. At the end of disciplines three reports were analyzed: 1-From access to contents: $A(2.603), B(229), C(463)$; 2Access to discipline: $A(477), B(157), C(263)$; 3-Stand online/h: $A(173), B(16)$, $C(41)$. There was a great variation in the frequency of users: major to $A$ and less to $B$ and $C$, some factors were observed: 1-Online agenda that remained at disposition of the students seems to guide and facilitate the access to A. 2-the fast answer from the teachers to the doubts of students seems to have increased the interest on A; 3-The dynamic of the group in the chat can have contributed with a better relationship on A. On B and C, the students were not able with the environment and this could be influenced in the results. The use of virtual environment in education is much more hard-working to the teachers than it is in presence and its applicability asks for new competency from users.

Keywords: Online education, biochemistry, virtual environment 